\title{
Relações lineares entre caracteres de aveia preta
}

\author{
Linear relations among characters of black oat
}

\begin{abstract}
Alberto Cargnelutti Filho' ${ }^{\mathrm{I}}$ Marcos Toebe ${ }^{\mathrm{II}}$ Bruna Mendonça Alves ${ }^{\mathrm{II}}$ Cláudia Burin ${ }^{\mathrm{II}}$ Gustavo Oliveira dos Santos"I Giovani FaccoII Ismael Mario Márcio Neu ${ }^{\text {III }}$
\end{abstract}

\section{RESUMO}

É importante estudar as relações lineares entre os caracteres para a seleção indireta de plantas. $O$ objetivo deste trabalho foi avaliar as relações lineares entre caracteres de aveia preta (Avena strigosa Schreb) e identificar caracteres para a seleção indireta. Foi conduzido experimento a campo e, em dez épocas de avaliação $(22,28,34,42,48,55,76,83,90$ e 105 dias após a semeadura), foram selecionadas, aleatoriamente, 52 plantas, totalizando 520 plantas. Em cada planta, foram mensurados os caracteres altura de planta, números de folhas e de perfilhos e as massas verde e seca. Foi ajustado o modelo sigmoidal e investigada a relação entre os caracteres por meio de análises de correlação e de trilha. Na cultura de aveia preta, o número de folhas por planta e a altura de planta têm relação linear positiva com as massas verde e seca e podem ser utilizados para seleção indireta.

Palavras-chave: Avena strigosa Schreb, análise de trilha, seleção indireta.

\section{ABSTRACT}

It is important to study the linear relations among characters for indirect selection of plants. The objective of this paper was to evaluate the linear relations among characters of black oat (Avena strigosa Schreb) and identify characters for indirect selection. Field experiment was conducted and in ten evaluation times (22, 28, $34,42,48,55,76,83,90$ and 105 days after sowing) were randomly selected 52 plants, totaling 520 plants. In each plant, were measured the characters plant height, number of leaves and number of tillers, and fresh and dry masses. The sigmoidal model was adjusted and it was studied the relations among the traits by correlation and path analysis. In the culture of black oat, the number of leaves per plant and plant height has a positive linear relation with the fresh and dry masses of shoots and can be used for indirect selection.
Key words: Avena strigosa Schreb, path analysis, indirect selection.

\section{INTRODUÇÃO}

A aveia (Avena strigosa Schreb) é um cereal de inverno cultivado em nível mundial, usada na alimentação humana e animal (BENIN et al., 2003; NIRMALAKUMARI et al., 2013) e para cobertura do solo (CAIERÃO et al., 2001), por apresentar boa adaptação a climas úmidos e frios e a solos de baixa fertilidade, enquanto a aveia branca (Avena sativa L.) é mais utilizada na produção de grãos (CAIERÃO et al., 2001). Segundo SALGADO et al. (2013), a utilização de aveia preta como planta forrageira, na alimentação de vacas leiteiras, aumenta o volume de leite com custos menores, em relação à utilização de outras dietas volumosas.

Em experimentos com plantas utilizadas na cobertura de solo, como é o caso de aveia preta, é comum a mensuração de diversos caracteres, que podem ou não estarem relacionados linearmente. Para a cobertura de solo, plantas com maiores quantidades de massas verde e seca são almejadas. A quantificação das massas verde e seca é de caráter destrutivo e, por isso, é importante conhecer as relações dessas massas com outros caracteres que possam ser mensurados de modo não destrutivo, e utilizados na seleção indireta e no melhoramento de plantas. O coeficiente

\footnotetext{
IDepartamento de Fitotecnia, Centro de Ciências Rurais (CCR), Universidade Federal de Santa Maria (UFSM), 97105-900, Santa Maria, RS, Brasil. E-mail: alberto.cargnelutti.filho@gmail.com. Autor para correspondência.

IIPrograma de Pós-graduação em Agronomia, UFSM, Santa Maria, RS, Brasil.

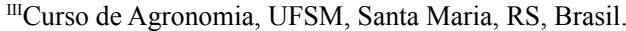


de correlação linear de Pearson pode ser utilizado como medida do grau de relacionamento entre dois caracteres e, no caso de mais de dois caracteres em estudo, a análise de trilha é apropriada e fornece informações importantes sobre as inter-relações entre os caracteres. $\mathrm{Na}$ análise de trilha, os coeficientes de correlação são desdobrados em efeitos diretos e indiretos, o que permite medir a influência de uma variável sobre a outra, independentemente das demais (CRUZ, 2006). Assim, é importante aplicar esses procedimentos estatísticos para identificar relações de causa e efeito entre caracteres, sendo que caracteres com relação de causa e efeito podem ser utilizados na seleção indireta de plantas.

Estudos de relações lineares entre caracteres de nabo forrageiro (Raphanus sativus L.) e de tremoço branco (Lupinus albus L.) indicaram que o diâmetro de caule e o número de vagens por planta, respectivamente, têm relação linear positiva com as massas verde e seca e podem ser utilizados para seleção indireta de plantas (CARGNELUTTI FILHO et al., 2014). Coeficientes de correlação e análise de trilha foram utilizados em estudos de associações entre caracteres de aveia branca (Avena sativa L.) por CAIERÃO et al. (2001), BENIN et al. (2003), MORADI et al. (2005), LORENCETTI et al. (2006), DUMLUPINAR et al. (2012), AHMED et al. (2013), NIRMALAKUMARI et al. (2013) e por ZAHERI et al. (2013). No entanto, não foram encontrados, na literatura, estudos de associações de caracteres não destrutivos, que poderiam ser utilizados para a seleção indireta de plantas com maiores produções de massas verde e seca de aveia preta. Assim, o objetivo deste trabalho foi avaliar as relações lineares entre caracteres de aveia preta e identificar caracteres para a seleção indireta.

\section{MATERIAL E MÉTODOS}

Foi conduzido um ensaio de uniformidade (experimento sem tratamentos, em que a cultura agrícola e todos os procedimentos realizados durante o experimento são homogêneos em toda a área experimental) com a cultura de aveia preta (Avena strigosa Schreb, cv. 'comum'), numa área experimental de $60 \mathrm{~m} \times 60 \mathrm{~m}$, localizada a $29^{\circ} 42^{\prime} \mathrm{S}$, $53^{\circ} 49^{\prime} \mathrm{W}$ e a $95 \mathrm{~m}$ de altitude. A semeadura de aveia preta foi realizada a lanço, em 14 de junho de 2012, na densidade de $100 \mathrm{~kg} \mathrm{ha}^{-1}$ e os tratos culturais foram realizados homogeneamente na área experimental. Em dez épocas de avaliação (22, 28, 34, 42, 48, $55,76,83,90$ e 105 dias após a semeadura - DAS), foram selecionadas, aleatoriamente, 52 plantas, totalizando 520 plantas. As plantas foram cortadas junto à superfície do solo e, logo a seguir, em cada planta, foram mensurados os caracteres altura de planta (AP), em $\mathrm{cm}$, número de folhas por planta (NF), número de perfilhos por planta (NP), massa verde (MV), em gramas planta ${ }^{-1}$ e massa seca (MS), em gramas planta ${ }^{-1}$.

Foi ajustado o modelo sigmoidal para cada caractere (AP, NF, NP, MV e MS) em função das épocas de avaliação $(22,28,34,42,48,55,76,83$, 90 e 105 DAS). Com os dados das 52 plantas, em cada época de avaliação, foram calculadas a média e o desvio-padrão para cada caractere. A seguir, para cada caractere, em cada época de avaliação, foram calculados os resíduos $\left(\mathrm{e}_{\mathrm{i}}\right)$ considerando o modelo matemático $Y_{i}=m+e_{i}$, em que $Y_{i}=$ valor observado do caractere na i-ésima planta $(\mathrm{i}=1,2, \ldots, 52) ; \mathrm{m}$ $=$ constante (média de 52 plantas) $\mathrm{e}_{\mathrm{i}}=$ resíduo da i-ésima planta $\left(e_{i}=Y_{i}-m\right)$. Esses resíduos $\left(e_{i}\right)$ foram utilizados no estudo das relações lineares entre os caracteres em cada época e no geral (todas as épocas). Em cada época de avaliação, o estudo das relações lineares por meio de $\mathrm{Y}_{i}$ ou $e_{i}$ levaria aos mesmos resultados (matrizes de correlação iguais). Mas, no geral (todas as épocas), o e $\mathrm{e}_{\mathrm{i}}$ deve ser utilizado, pois é livre da influência de épocas de avaliação.

Com base nos resíduos $\left(\mathrm{e}_{\mathrm{i}}\right)$, para cada época de avaliação $(22,28,34,42,48,55,76,83$, 90 e 105 DAS) e no geral (todas as épocas), foi calculada a matriz de coeficientes de correlação linear de Pearson (r) entre os caracteres AP, NF, NP, MV e MS e, por meio do teste t de Student, a 5\% de probabilidade, foi verificada a significância do $\mathrm{r}$. Foi realizado o diagnóstico de multicolinearidade (CRUZ, 2006) e interpretado de acordo com critério de MONTGOMERY \& PECK (1982). Depois disso, foram realizadas análises de trilha das variáveis principais (MV e MS) em função das variáveis explicativas (AP, NF e NP). As análises estatísticas foram realizadas com o programa GENES (CRUZ, 2006) e o Microsoft Office Excel ${ }^{\circledR}$.

\section{RESULTADOS E DISCUSSÃO}

De maneira geral, a média dos caracteres AP, NF, NP, MV e MS apresentou leves incrementos nas primeiras épocas de avaliação (22, 28 e 34 DAS), altos acréscimos nas épocas intermediárias (42, $48,55,76,83$ DAS) e tendência de estabilização nas últimas épocas (90 e 105 DAS). Essas médias revelaram adequado desenvolvimento das plantas, refletindo condições reais de experimentos a campo e apresentaram ajuste razoável $\left(0,45 \leq R^{2} \leq 0,96\right)$ 
ao modelo sigmoidal (Figuras 1A, 1B, 1C, 1D e 1E). É provável que outros modelos matemáticos apresentem melhores ajustes, principalmente, para $\mathrm{NP}\left(\mathrm{R}^{2}=0,45\right.$; Figura $\left.1 \mathrm{C}\right)$, porém, investigações mais detalhadas sobre modelos de crescimento não foram o foco deste trabalho.
Em estudo desenvolvido por ROSSETTO \& NAKAGAWA (2001), houve aumento da altura de plantas de aveia preta, nas seis avaliações realizadas entre 21 e 126 dias após emergência (DAE), sendo, no entanto, menos evidente após a emissão das panículas, aos 84 DAE. Os autores também
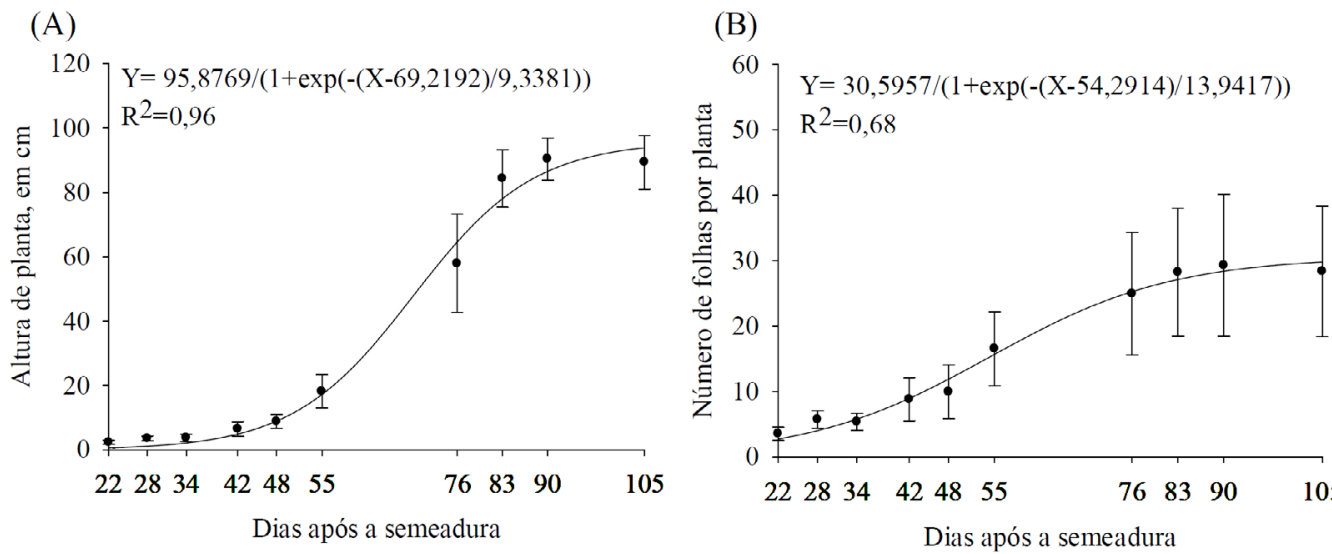

(C)

(D)
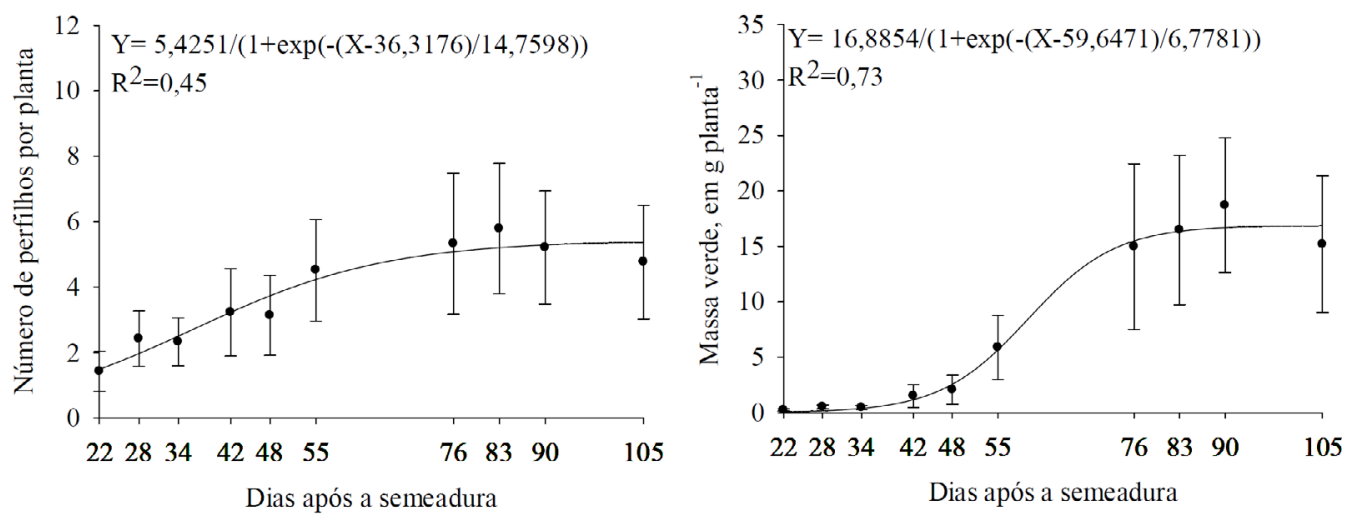

(E)

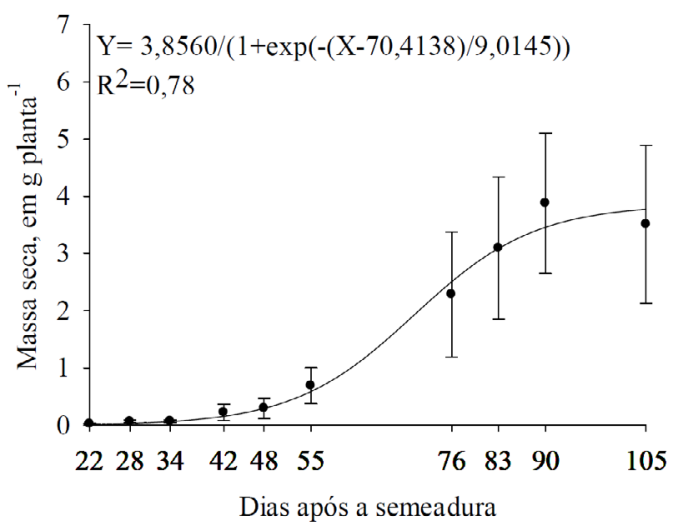

Figura 1 - Representação gráfica do modelo sigmoidal dos caracteres altura de planta (A), número de folhas por planta (B), número de perfilhos por planta (C), massa verde (D) e massa seca (E) em função de épocas de avaliação $(22,28,34,42,48,55,76,83,90$ e 105 dias após a semeadura). As barras verticais representam a média \pm desviopadrão estimadas com base em 52 plantas de aveia preta (Avena strigosa Schreb), em cada época de avaliação. 
verificaram tendência de redução do número de folhas por planta e do número de perfilhos por planta a partir de $84 \mathrm{DAE}$, época esta que coincide com a avaliação realizada aos 90 DAS no presente estudo. Os valores de AP aos 105 DAS obtidos no presente estudo (Figura 1A) são similares aos verificados por NIRMALAKUMARI et al. (2013) no final do ciclo de 21 genótipos de aveia branca, nos quais foi verificada altura média de $109,14 \mathrm{~cm}$, oscilando entre 87,8 e $140,5 \mathrm{~cm}$. Em estudo desenvolvido por BUERSTMAYR et al. (2007), em 120 genótipos de aveia branca, a altura de plantas oscilou entre 80 e $140 \mathrm{~cm}$, sendo que as cultivares mais produtivas apresentavam altura de plantas entre 100 e $120 \mathrm{~cm}$. Já BIBI et al. (2012) verificaram que a altura de plantas oscilou entre 66,2 e 175,3cm, em 108 acessos de aveia branca. Em relação ao número de perfilhos, verificouse que os valores obtidos na última avaliação (105 DAS; Figura 1C) são similares aos verificados por NIRMALAKUMARI et al. (2013) no final do ciclo de genótipos de aveia branca, nos quais foram verificados, em média, 8,52 perfilhos basais, oscilando entre 3,30 e 15,67 perfilhos por planta.

Para os caracteres AP, NF, NP, MV e MS de plantas de aveia preta, houve acréscimo do desviopadrão no sentido das épocas iniciais para as épocas finais de avaliação (Figuras 1A, 1B, 1C, 1D e 1E). A variabilidade existente entre as plantas é importante e confere adequabilidade ao estudo das relações lineares entre os caracteres, por meio das análises de correlação e de trilha. Assim, é possível que as relações lineares entre os caracteres estejam melhor estabelecidas nas épocas com maior variabilidade (maior desvio-padrão). Dessa forma, é esperado maior confiabilidade nos resultados com os dados das avaliações finais em relação às iniciais. Então, diante das considerações, em relação ao adequado desenvolvimento das plantas e à variabilidade dos dados, aliado ao elevado número de plantas avaliadas (52 plantas por época $\times 10$ épocas $=520$ plantas $)$, pode-se inferir que esse banco de dados oferece credibilidade ao estudo de relações lineares entre esses caracteres.

Com base nas 520 plantas, os coeficientes de correlação linear de Pearson (r) entre os caracteres de aveia preta $(0,107 \leq \mathrm{r} \leq 0,940)$ (Tabela 1$)$ revelam associações lineares positivas. Associações positivas entre caracteres também foram verificadas mediante o uso de correlações genotípicas e fenotípicas em aveia branca por NIRMALAKUMARI et al. (2013). Ainda em aveia branca, AHMAD et al. (2013) observaram que a massa verde apresentou correlação positiva com a altura de plantas, número de folhas, número de perfilhos e com a massa seca de plantas. O grau de associação linear entre os pares de caracteres $\mathrm{AP} \times \mathrm{NF}(\mathrm{r}=0,202)$ e $\mathrm{AP} \times \mathrm{NP}(\mathrm{r}=0,107)$ foi, relativamente, menor quando comparado ao grau de associação linear entre os demais oito pares de caracteres $(0,493 \leq r \leq 0,940$; Tabela 1$)$. Maior grau de associação linear (maiores valores de r) desses oito pares de caracteres, em relação aos pares $\mathrm{AP} \times \mathrm{NF}$ e $\mathrm{AP} \times \mathrm{NP}$, foi constatado nas dez épocas de avaliação $(22,28,34,42,48,55,76,83,90$ e 105 DAS $)$, o que revela padrões de linearidade semelhantes nas épocas de avaliação e no geral (todas as épocas).

Entre os caracteres AP, NF e NP, os coeficientes de correlação (r) nas dez épocas de avaliação e no geral (todas as épocas) revelaram maior grau de associação linear positiva entre $\mathrm{NF} \times \mathrm{NP}(0,700 \leq \mathrm{r} \leq 0,915$; Tabela 1$)$, o que indica que plantas de aveia preta com maior número de perfilhos possuem maior número de folhas e vice-versa. Entre os pares de caracteres $\mathrm{AP} \times \mathrm{NF}$ e $\mathrm{AP} \times \mathrm{NP}$, na maioria das épocas, não houve correlação linear e, no geral, apesar do $r$ apresentar significância estatística, pelo elevado número de plantas $(n=520)$, foi de baixa magnitude $(r \leq 0,202)$ e sem significância prática (HAIR et al., 2009). Assim, pode-se inferir que entre esses três caracteres houve maior associação linear entre $\mathrm{NF} \times \mathrm{NP}$ quando comparada às associações lineares entre os pares de caracteres $\mathrm{AP} \times \mathrm{NF}$ e $\mathrm{AP} \times \mathrm{NP}$. Em trabalho conduzido por BIBI et al. (2012), em 108 acessos de aveia branca, foi verificada correlação genotípica negativa e de baixa magnitude entre altura de plantas e número de perfilhos $\mathrm{m}^{-2}$ $\left(r_{g}=-0,127\right)$, mas correlação positiva e significativa entre altura de plantas e número de folhas na haste principal $\left(\mathrm{r}_{\mathrm{g}}=0,439\right)$. Os autores também verificaram correlação negativa entre o número de folhas na haste principal e o número de perfilhos $\mathrm{m}^{-2}\left(\mathrm{r}_{\mathrm{g}}=\right.$ -0,563). As diferenças de magnitudes e sentidos entre as correlações obtidas por BIBI et al. (2012), com as do presente estudo, podem estar associadas à forma de mensuração dessas variáveis, visto que, no presente trabalho, o NP foi mensurado por planta e não por $\mathrm{m}^{2}$, conforme mensuração de BIBI et al. (2012). Além disso, na mensuração de NF, foram consideradas todas as folhas por planta e não apenas as folhas da haste principal, conforme BIBI et al. (2012). Em trabalho desenvolvido por AHMAD et al. (2013), foi verificada correlação genotípica positiva entre o número de perfilhos $\mathrm{m}^{-2}$ e o número de folhas por planta $\left(\mathrm{r}_{\mathrm{g}}=0,4126\right)$ e entre $\mathrm{AP} \times \mathrm{NP}$ $\left(r_{g}=0,2479\right)$ e entre $\mathrm{AP} \times \stackrel{\mathrm{N} F}{\mathrm{~N}}\left(\mathrm{r}_{\mathrm{g}}=0,2783\right)$. Os autores também constataram correlação positiva entre $\mathrm{MV} \times \mathrm{AP} \quad\left(\mathrm{r}_{\mathrm{g}}=0,3385\right)$, entre $\mathrm{MV} \times \mathrm{NP} \quad\left(\mathrm{r}_{\mathrm{g}}=0,3455\right)$

Ciência Rural, v.45, n.6, jun, 2015. 
Tabela 1 - Estimativas dos coeficientes de correlação linear de Pearson (r) e dos efeitos diretos e indiretos (análise de trilha) entre os resíduos (valor observado menos a média) dos caracteres altura de planta (AP), número de folhas por planta (NF), número de perfilhos por planta (NP) sobre a massa verde (MV) e a massa seca (MS) de aveia preta (Avena strigosa Schreb) em dez épocas de avaliação (22, 28, 34, 42, 48, 55, 76, 83, 90 e 105 dias após a semeadura - DAS) e no geral (todas as épocas). Em cada época, foram avaliadas 52 plantas, totalizando 520 plantas.

\begin{tabular}{|c|c|c|c|c|c|c|c|c|c|c|c|}
\hline Caracteres & 22DAS & 28DAS & 34DAS & 42DAS & 48DAS & 55DAS & 76DAS & 83DAS & 90DAS & 105DAS & Geral \\
\hline $\mathrm{AP} \times \mathrm{NF}$ & $-0,045 \mathrm{~ns}$ & $-0,185 \mathrm{~ns}$ & $0,303^{*}$ & $0,135 \mathrm{~ns}$ & $0,557^{*}$ & $0,121 \mathrm{~ns}$ & $0,246 \mathrm{~ns}$ & $0,363^{*}$ & $0,116 \mathrm{~ns}$ & $0,109 \mathrm{~ns}$ & $0,202 *$ \\
\hline $\mathrm{AP} \times \mathrm{NP}$ & $-0,003 \mathrm{~ns}$ & $-0,221 \mathrm{~ns}$ & $0,016 \mathrm{~ns}$ & $0,099 \mathrm{~ns}$ & $0,449^{*}$ & $0,052 \mathrm{~ns}$ & $-0,009 \mathrm{~ns}$ & $0,328 *$ & $0,106 \mathrm{~ns}$ & $0,161 \mathrm{~ns}$ & $0,107^{*}$ \\
\hline $\mathrm{AP} \times \mathrm{MV}$ & $0,526^{*}$ & $0,504 *$ & $0,685^{*}$ & $0,562 *$ & $0,801 *$ & $0,490^{*}$ & $0,639^{*}$ & $0,497 *$ & $0,419^{*}$ & $0,555^{*}$ & $0,539 *$ \\
\hline $\mathrm{AP} \times \mathrm{MS}$ & $0,338^{*}$ & $0,453^{*}$ & $0,596^{*}$ & $0,494 *$ & $0,777^{*}$ & $0,400^{*}$ & $0,629^{*}$ & $0,574 *$ & $0,392^{*}$ & $0,534^{*}$ & $0,505^{*}$ \\
\hline $\mathrm{NF} \times \mathrm{NP}$ & $0,750^{*}$ & $0,900^{*}$ & $0,700^{*}$ & $0,885^{*}$ & $0,911^{*}$ & $0,915^{*}$ & $0,839 *$ & $0,830^{*}$ & $0,789^{*}$ & $0,826^{*}$ & $0,801 *$ \\
\hline $\mathrm{NF} \times \mathrm{MV}$ & $0,541^{*}$ & $0,407^{*}$ & $0,618^{*}$ & $0,751^{*}$ & $0,806^{*}$ & $0,763^{*}$ & $0,706^{*}$ & $0,729^{*}$ & $0,771^{*}$ & $0,563^{*}$ & $0,686^{*}$ \\
\hline $\mathrm{NF} \times \mathrm{MS}$ & $0,592^{*}$ & $0,423^{*}$ & $0,602 *$ & $0,795^{*}$ & $0,817^{*}$ & $0,749^{*}$ & $0,746^{*}$ & $0,757 *$ & $0,660^{*}$ & $0,619^{*}$ & $0,674 *$ \\
\hline $\mathrm{NP} \times \mathrm{MV}$ & $0,476^{*}$ & $0,390^{*}$ & $0,545^{*}$ & $0,662^{*}$ & $0,671^{*}$ & $0,614^{*}$ & $0,434 *$ & $0,672 *$ & $0,594 *$ & $0,493^{*}$ & $0,506^{*}$ \\
\hline $\mathrm{NP} \times \mathrm{MS}$ & $0,461^{*}$ & $0,397 *$ & $0,617^{*}$ & $0,699 *$ & $0,681^{*}$ & $0,576^{*}$ & $0,487^{*}$ & $0,671^{*}$ & $0,524 *$ & $0,538^{*}$ & $0,493^{*}$ \\
\hline $\mathrm{MV} \times \mathrm{MS}$ & $0,916^{*}$ & $0,981 *$ & $0,974 *$ & $0,991 *$ & $0,989 *$ & $0,973^{*}$ & $0,966^{*}$ & $0,946^{*}$ & $0,932 *$ & $0,973^{*}$ & $0,940 *$ \\
\hline Efeito & & & & ----Análi & de trilhe & $M V=f u$ & ฉีค & $\mathrm{NP}$ & & & \\
\hline Direto de AP sobre MV & 0,548 & 0,617 & 0,650 & 0,469 & 0,492 & 0,381 & 0,448 & 0,262 & 0,334 & 0,501 & 0,414 \\
\hline Indireto de AP via NF & $-0,021$ & $-0,046$ & 0,028 & 0,089 & 0,401 & 0,129 & 0,189 & 0,172 & 0,090 & 0,058 & 0,131 \\
\hline Indireto de AP via NP & 0,000 & $-0,067$ & 0,007 & 0,003 & $-0,092$ & $-0,020$ & 0,002 & 0,063 & $-0,006$ & $-0,004$ & $-0,006$ \\
\hline Correlação de Pearson (r) & $0,526^{*}$ & $0,504 *$ & $0,685^{*}$ & $0,562 *$ & $0,801^{*}$ & $0,490^{*}$ & $0,639^{*}$ & $0,497 *$ & $0,419^{*}$ & $0,555^{*}$ & $0,539 *$ \\
\hline Direto de NF sobre MV & 0,474 & 0,250 & 0,092 & 0,658 & 0,719 & 1,063 & 0,767 & 0,473 & 0,773 & 0,528 & 0,650 \\
\hline Indireto de $\mathrm{NF}$ via $\mathrm{AP}$ & $-0,025$ & $-0,114$ & 0,197 & 0,063 & 0,274 & 0,046 & 0,110 & 0,095 & 0,039 & 0,055 & 0,084 \\
\hline Indireto de NF via NP & 0,092 & 0,271 & 0,329 & 0,029 & $-0,187$ & $-0,346$ & $-0,171$ & 0,160 & $-0,041$ & $-0,019$ & $-0,048$ \\
\hline Correlação de Pearson (r) & $0,541^{*}$ & $0,407^{*}$ & $0,618^{*}$ & $0,751^{*}$ & $0,806^{*}$ & $0,763^{*}$ & $0,706^{*}$ & $0,729^{*}$ & $0,771 *$ & $0,563^{*}$ & $0,686^{*}$ \\
\hline Direto de NP sobre MV & 0,122 & 0,301 & 0,470 & 0,033 & $-0,205$ & $-0,378$ & $-0,204$ & 0,193 & $-0,052$ & $-0,023$ & $-0,059$ \\
\hline Indireto de NP via AP & $-0,002$ & $-0,136$ & 0,010 & 0,046 & 0,221 & 0,020 & $-0,004$ & 0,086 & 0,035 & 0,081 & 0,044 \\
\hline Indireto de NP via NF & 0,355 & 0,225 & 0,065 & 0,582 & 0,655 & 0,972 & 0,643 & 0,393 & 0,610 & 0,436 & 0,521 \\
\hline Correlação de Pearson (r) & $0,476^{*}$ & $0,390 *$ & $0,545^{*}$ & $0,662 *$ & $0,671^{*}$ & $0,614^{*}$ & $0,434^{*}$ & $0,672 *$ & $0,594 *$ & $0,493^{*}$ & $0,506^{*}$ \\
\hline Coeficiente determinação & 0,603 & 0,531 & 0,759 & 0,779 & 0,836 & 0,766 & 0,739 & 0,605 & 0,706 & 0,564 & 0,640 \\
\hline Variável residual & 0,630 & 0,685 & 0,491 & 0,470 & 0,405 & 0,484 & 0,511 & 0,628 & 0,542 & 0,661 & 0,600 \\
\hline Número de condição & 7,05 & 20,00 & 7,28 & 16,74 & 28,84 & 23,41 & 15,17 & 12,12 & 8,64 & 10,82 & 9,62 \\
\hline Direto de AP sobre MS & 0,365 & 0,564 & 0,587 & 0,394 & $\begin{array}{c}\text { se de trilh } \\
0,447\end{array}$ & $\begin{array}{l}\mathrm{MS}=\mathrm{fu} \\
0,280\end{array}$ & $\begin{array}{c}\text { ção (AP, N } \\
0,441\end{array}$ & $\begin{array}{l}\text { NP) --- } \\
0,342\end{array}$ & 0,319 & 0,473 & 0,380 \\
\hline Indireto de $\mathrm{AP}$ via $\mathrm{NF}$ & $-0,027$ & $-0,056$ & $-0,001$ & 0,098 & 0,427 & 0,150 & 0,187 & 0,196 & 0,073 & 0,064 & 0,132 \\
\hline Indireto de AP via NP & 0,000 & $-0,055$ & 0,010 & 0,002 & $-0,098$ & $-0,029$ & 0,001 & 0,036 & 0,000 & $-0,003$ & $-0,008$ \\
\hline Correlação de Pearson (r) & $0,338^{*}$ & $0,453^{*}$ & $0,596^{*}$ & $0,494^{*}$ & $0,777^{*}$ & $0,400^{*}$ & $0,629 *$ & $0,574 *$ & $0,392 *$ & $0,534^{*}$ & $0,505^{*}$ \\
\hline Direto de NF sobre MS & 0,600 & 0,301 & $-0,003$ & 0,726 & 0,767 & 1,235 & 0,759 & 0,542 & 0,626 & 0,585 & 0,655 \\
\hline Indireto de NF via AP & $-0,016$ & $-0,104$ & 0,178 & 0,053 & 0,249 & 0,034 & 0,109 & 0,124 & 0,037 & 0,052 & 0,077 \\
\hline Indireto de NF via NP & 0,009 & 0,226 & 0,427 & 0,015 & $-0,199$ & $-0,520$ & $-0,122$ & 0,091 & $-0,003$ & $-0,017$ & $-0,058$ \\
\hline Correlação de Pearson (r) & $0,592^{*}$ & $0,423 *$ & $0,602 *$ & $0,795^{*}$ & $0,817^{*}$ & $0,749^{*}$ & $0,746^{*}$ & $0,757^{*}$ & $0,660^{*}$ & $0,619^{*}$ & $0,674^{*}$ \\
\hline Direto de NP sobre MS & 0,012 & 0,251 & 0,610 & 0,017 & $-0,218$ & $-0,568$ & $-0,145$ & 0,110 & $-0,004$ & $-0,021$ & $-0,072$ \\
\hline Indireto de NP via AP & $-0,001$ & $-0,125$ & 0,009 & 0,039 & 0,201 & 0,015 & $-0,004$ & 0,112 & 0,034 & 0,076 & 0,041 \\
\hline Indireto de NP via NF & 0,450 & 0,271 & $-0,002$ & 0,643 & 0,699 & 1,130 & 0,636 & 0,449 & 0,494 & 0,483 & 0,525 \\
\hline Correlação de Pearson (r) & $0,461 *$ & $0,397^{*}$ & $0,617^{*}$ & $0,699 *$ & $0,681 *$ & $0,576^{*}$ & $0,487 *$ & $0,671^{*}$ & $0,524 *$ & $0,538^{*}$ & $0,493 *$ \\
\hline Coeficiente determinação & 0,484 & 0,483 & 0,724 & 0,784 & 0,825 & 0,710 & 0,773 & 0,680 & 0,536 & 0,603 & 0,598 \\
\hline Variável residual & 0,718 & 0,719 & 0,525 & 0,465 & 0,418 & 0,539 & 0,476 & 0,566 & 0,681 & 0,630 & 0,634 \\
\hline Número de condição & 7,05 & 20,00 & 7,28 & 16,74 & 28,84 & 23,41 & 15,17 & 12,12 & 8,64 & 10,82 & 9,62 \\
\hline
\end{tabular}

* Significativo a 5\% de probabilidade de erro pelo teste t, com 50 graus de liberdade para cada época de avaliação e com 518 graus de liberdade para o geral (todas as épocas). $\mathrm{ns}=$ Não significativo. 
e entre $\mathrm{MV} \times \mathrm{NF}\left(\mathrm{r}_{\mathrm{g}}=0,5423\right)$. Entre os caracteres $\mathrm{MV} \times \mathrm{MS}$, houve elevada associação linear positiva $(0,916 \leq r \leq 0,991$; Tabela 1$)$, como esperado, ou seja, plantas com maior MV possuem maior MS e viceversa. Associação positiva entre os caracteres massa verde e massa seca também foi verificada para aveia branca por BIBI et al. (2012) e AHMAD et al. (2013).

De maneira geral, as massas verde (MV) e seca (MS) de aveia preta apresentaram maior grau de associação linear positiva (maiores valores de $\mathrm{r}$ ) com o NF e menor grau de associação com AP e NP, que foram semelhantes entre si (Tabela 1). Portanto, esses resultados sugerem que plantas de aveia preta com maior número de folhas possuem maiores massas verde e seca. Em aveia branca, NIRMALAKUMARI et al. (2013) verificaram que o número de perfilhos basais apresentou elevada correlação genotípica $\left(r_{\mathrm{g}}=0,77\right)$ e fenotípica $\left(\mathrm{r}_{\mathrm{f}}=0,68\right)$ com a produtividade de grãos e, por outro lado, a altura de plantas apresentou correlação de pequena magnitude com a produtividade de grãos $\left(\mathrm{r}_{\mathrm{g}}=0,14\right.$ e $\left.\mathrm{r}_{\mathrm{f}}=0,13\right)$. Os autores também verificaram correlação genotípica $\left(\mathrm{r}_{\mathrm{g}}=0,50\right)$ e fenotípica $\left(r_{\mathrm{f}}=0,44\right)$ significativa entre massa seca e produtividade de grãos e correlação genotípica $\left(r_{\mathrm{g}}=0,41\right)$ e fenotípica $\left(\mathrm{r}_{\mathrm{f}}=0,37\right)$ significativa entre nú̉mero de perfilhos basais e massa seca de aveia branca, próxima à correlação de Pearson geral, obtida no presente estudo, de $\mathrm{r}=0,493$ (Tabela 1). A correlação genotípica $\left(r_{\mathrm{g}}=0,55\right)$ e fenotípica $\left(r_{\mathrm{f}}=0,48\right)$ significativa entre número de perfilhos e massa verde, obtida por NIRMALAKUMARI et al. (2013) para aveia branca, também foi próxima a obtida no presente estudo $(\mathrm{r}=0,506)$ para aveia preta. Segundo NIRMALAKUMARI et al. (2013), em aveia branca, tanto o número de perfilhos por planta quanto a massa seca, além de outras variáveis, contribuem positivamente para a maior produtividade de grãos por planta. Ainda em aveia branca, BIBI et al. (2012) obtiveram correlações de baixa magnitude entre $\mathrm{AP} \times \mathrm{MV} \quad\left(\mathrm{r}_{\mathrm{g}}=-0,065\right), \mathrm{AP} \times \mathrm{MS} \quad\left(\mathrm{r}_{\mathrm{g}}=0,211\right), \mathrm{NP} \times \mathrm{MV}$ $\left(r_{\mathrm{g}}=0,242\right)$ e $\mathrm{NP} \times \mathrm{MS}\left(\mathrm{r}_{\mathrm{g}}=0,246\right)$. Apenas por meio dos coeficientes de correlação, não é possível inferir qual dos caracteres tem efeito direto nas massas verde e seca. Assim, a análise de trilha é um procedimento adequado para inferir sobre as verdadeiras relações de causa e efeito entre os caracteres.

O diagnóstico de multicolinearidade na matriz de coeficientes de correlação linear de Pearson (r), entre as variáveis explicativas AP, NF e NP, revelou número de condição (NC) entre 7,05 (avaliação aos 22 DAS) e 28,84 (avaliação aos 48 DAS) (Tabela 1). Portanto, as matrizes apresentaram colinearidade baixa, conforme critério de MONTGOMERY \& PECK (1982). Assim, as análises de trilha das massas verde (MV) e seca (MS) de aveia preta, em função das variáveis explicativas AP, NF e NP, podem ser realizadas adequadamente.

Os resultados das análises de trilha da MV e da MS em função da AP, NF e NP, nas três primeiras épocas de avaliação (22, 28 e 34 DAS), foram distintos das outras sete épocas de avaliação $(42,48,55,76,83,90$ e 105 DAS) e do geral (todas as épocas) (Tabela 1). Nas primeiras épocas de avaliação (22, 28 e 34 DAS), as plantas estavam no início do crescimento e desenvolvimento e apresentavam menor variabilidade (menor desvio-padrão), quando comparadas às demais épocas (Figura 1). A menor variabilidade entre as plantas pode explicar as relações lineares, provavelmente ainda não estabelecidas entre esses caracteres.

Aos 22, 28 e 34 DAS, a MV apresentou correlação linear positiva $(r=0,526,0,504$ e 0,685 , respectivamente) e efeito direto $(0,548,0,617$ e 0,650 , respectivamente), com mesmo sinal e de magnitude semelhante com a AP, o que explica a verdadeira associação existente (Tabela 1). Portanto, pode-se inferir que, nas primeiras épocas de avaliação (22, 28 e 34 DAS), plantas com maior altura são aquelas com maior massa verde. Porém, nas outras sete épocas de avaliação (42, 48, 55, 76, 83, 90 e 105 DAS) e no geral (todas as épocas), a MV apresentou correlação linear positiva $(0,563 \leq r \leq 0,806)$ e efeito direto $(0,473 \leq$ efeito direto $\leq 1,063$ ) com mesmo sinal e de magnitude semelhante com o NF, o que revela relação de causa e efeito entre NF e MV. Ainda, em menor magnitude, nas sete épocas finais de avaliação $(42,48,55,76,83$, 90 e 105 DAS) e no geral (todas as épocas), a MV apresentou correlação linear positiva $(0,419 \leq \mathrm{r} \leq 0,801)$ e efeito direto $(0,262 \leq$ efeito direto $\leq 0,501)$ com mesmo sinal e de magnitude semelhante com a AP, confirmando relação de causa e efeito entre AP e MV. Também a MV apresentou correlação linear positiva $(0,434 \leq r \leq 0,672)$ com o NP. No entanto, os efeitos diretos do $\mathrm{NP}(-0,378 \leq$ efeito direto $\leq 0,193)$ sobre a MV foram de sinais opostos e/ou desprezíveis e, portanto, a associação existente é explicada pelos maiores efeitos indiretos via $\mathrm{NF}(0,393 \leq$ efeito indireto $\leq 0,972)$. Assim, de maneira geral, considerando a maior confiabilidade (maior variabilidade) das inferências, realizadas com base nas sete últimas avaliações e no geral (todas as épocas), pode-se concluir que plantas com maior número de folhas e com maior altura, nessa ordem, são aquelas com maior massa verde. Em relação à massa seca (MS), os resultados foram semelhantes, o que pode ser explicado pela forte associação linear 
$(0,916 \leq r \leq 0,991)$, entre MV e MS (Tabela 1$)$. Portanto, pode-se inferir que a seleção indireta para a MV e a MS deve ser realizada com base no número de folhas e na altura de planta. Esses resultados estão de acordo com os resultados obtidos em 75 linhagens de aveia branca, por AHMED et al. (2013), que verificaram maiores efeitos diretos de comprimento de folha, do número de folhas por planta e da altura de plantas sobre a produção de forragem (massa) verde. Os autores também constataram que a produção de massa verde teve o maior efeito direto sobre a produtividade de grãos.

O estudo da associação entre caracteres, mediante o uso de coeficientes de correlação fenotípicos e análise de trilha, foi verificada por CAIERÃO et al. (2001) em 58 linhagens de aveia branca. Os autores constataram que nenhum caractere apresentou correlação e efeito direto semelhante (de mesmo sinal e magnitude) sobre a produtividade de grãos, impedindo a seleção indireta de plantas mais produtivas com base em um único caractere. $\mathrm{O}$ estudo da associação linear entre caracteres, pelos coeficientes de correlação fenotípicos, genotípicos e ambientais e de análise de trilha também foi realizado por BENIN et al. (2003) em aveia branca, sendo que, de acordo com os autores, os caracteres peso de panícula, número de panículas por planta e peso médio de grãos podem ser utilizados na identificação de plantas de elevada produção de grãos. Já em estudo desenvolvido por MORADI et al. (2005), utilizando análise de trilha, foi constatado que o número de panículas e o número de grãos por panícula apresentaram os maiores efeitos diretos sobre a produtividade de grãos de aveia branca. Ainda em aveia branca, LORENCETTI et al. (2006) utilizaram correlação fenotípica, correlação canônica e análise de trilha para a identificação das relações de causa e efeito entre caracteres explicativos e a produtividade de grãos, visando à seleção indireta de plantas. Os autores verificaram que o número de panículas por plantas foi o caractere que apresentou maior relação de causa e efeito sobre a produtividade de grãos.

Em 17 genótipos de aveia branca, DUMLUPINAR et al. (2012) verificaram, com base nos coeficientes de correlação de Pearson e na análise de trilha, que o período de enchimento de grãos, o número de panículas $\mathrm{m}^{-2}$, o número de dias para maturação e a altura de plantas devem ser consideradas para a seleção indireta de plantas mais produtivas. A correlação genotípica e a análise de trilha também foram utilizadas por NIRMALAKUMARI et al. (2013) para o estudo de relações lineares entre 12 caracteres morfológicos e produtivos, avaliados em
21 genótipos de aveia branca. Os elevados valores negativos e positivos de efeitos diretos e indiretos de alguns caracteres sobre a produtividade de grãos $(-2,47 \leq$ efeito direto $\leq 2,82)$ podem estar relacionados a possíveis problemas de multicolinearidade entre as variáveis explicativas (TOEBE \& CARGNELUTTI FILHO, 2013). Assim, os reduzidos valores de efeitos diretos e indiretos da altura de plantas e do número de perfilhos por plantas sobre a produtividade de grãos, podem ser devidos a possíveis problemas na análise de trilha no referido estudo. Os autores constataram que o número de perfilhos produtivos por planta e o número de grãos por panícula são os principais componentes do rendimento e podem ser utilizados na seleção indireta de genótipos de alta produtividade de grãos de aveia branca. Além disso, os autores indicaram a importância do uso de correlações e análise de trilha para o entendimento das relações existentes entre os componentes do rendimento de aveia. Ainda em aveia branca, ZAHERI et al. (2013) verificaram que o número de panículas $\mathrm{m}^{-2}$ exerce maior efeito direto sobre a produtividade de grãos. No entanto, não foram encontrados, na literatura, estudos de relações lineares entre caracteres de aveia preta.

$\mathrm{Na}$ prática, os resultados obtidos no presente estudo evidenciam que é possível selecionar as plantas de aveia preta na área experimental, por meio da contagem do número de folhas ou da medição da altura de planta, sem a necessidade de destruir as plantas para a colheita. Isso é importante, pois possibilita, de modo não destrutivo, selecionar as plantas com maiores massas verde e seca e ainda avaliar a produtividade de grãos e obter sementes.

\section{CONCLUSÃO}

$\mathrm{Na}$ cultura de aveia preta, o número de folhas por planta e a altura de planta têm relação linear positiva com as massas verde e seca e podem ser utilizados para seleção indireta.

\section{AGRADECIMENTOS}

Ao Conselho Nacional de Desenvolvimento Científico e Tecnológico (CNPq) e à Coordenação de Aperfeiçoamento de Pessoal de Nível Superior (CAPES), pela concessão de bolsas aos autores. À Fundação de Amparo à Pesquisa do Estado do Rio Grande do Sul (FAPERGS), pela bolsa de iniciação científica e auxílio financeiro. Aos alunos bolsistas e voluntários, pelo auxílio na coleta de dados.

\section{REFERÊNCIAS}

AHMAD, M. et al. Estimation of correlation coefficient in oats (Avena sativa L.) for forage yield, grain yield and their contributing 
traits. International Journal of Plant Breeding and Genetics, v.7, p.188-191, 2013. Disponível em: < http://scialert.net/qredirect. php?doi=ijpbg.2013.188.191\&linkid=pdf $>$. Acesso em: 03 abr. 2014. doi: 10.3923/ijpbg.2013.188.191.

AHMED, S. et al. Correlation and path coefficient analysis for fodder and grain yield related traits in oats (Avena sativa L.). Annals of Biology, v.29, p.75-78, 2013. Disponível em: <http:// www.cabi.org/cabdirect/FullTextPDF/2013/20133068262.pdf>. Acesso em: 03 abr. 2014.

BENIN, G. et al. Estimativas de correlações e coeficientes de trilha como critérios de seleção para rendimento de grãos em aveia. Revista Brasileira de Agrociência, v.9, p.9-16, 2003. Disponível em: <http://www2.ufpel.edu.br/faem/agrociencia/v9n1/artigo02. pdf>. Acesso em: 03 abr. 2014.

BIBI, A. et al. Genetic characterization and inheritance studies of oats (Avena sativa L.) for green fodder yield. International Journal of Biology, Pharmacy and Allied Sciences, v.1, p.450-460, 2012. Disponível em: <http://ijbpas. com/pdf/1336903052MS\%20IJBPAS\%202012\%201084.pdf>. Acesso em: 03 abr. 2014.

BUERSTMAYR, H. et al. Agronomic performance and quality of oat (Avena sativa L.) genotypes of worldwide origin produced under Central European growing conditions. Field Crops Research, v.101, p.343-351, 2007. Disponível em: <http://www. sciencedirect.com/science/article/pii/S0378429006002553>. Acesso em: 03 abr. 2014.

CAIERÃO, E. et al. Seleção indireta em aveia para o incremento no rendimento de grãos. Ciência Rural, v.31, p.231-236, 2001. Disponível em: <http://www.scielo.br/pdf/cr/v31n2/a07v31n2. pdf>. Acesso em: 03 abr. 2014.

CARGNELUTTI FILHO, A. et al. Relações lineares entre caracteres de nabo forrageiro e de tremoço branco. Ciência Rural, v.44, p.18-24, 2014. Disponível em: <http://www.scielo.br/pdf/cr/ v44n1/a2014cr2012-0089.pdf>. Acesso em: 03 abr. 2014.

CRUZ, C.D. Programa genes: estatística experimental e matrizes. Viçosa: UFV, 2006. 285p.
DUMLUPINAR, Z . et al. Correlation and path analysis of grain yield and yield components of some Turkish oat genotypes. Pakistan Journal of Botany, v.44, p.321-325, 2012.

HAIR, J.F. et al. Análise multivariada de dados. 6.ed. Porto Alegre: Bookman, 2009. 688p.

LORENCETTI, C. et al. Aplicability of phenotypic and canonic correlations and path coefficients in the selection of oat genotypes. Scientia Agricola, v.63, p.11-19, 2006. Disponível em: <http:// www.scielo.br/pdf/sa/v63n1/27897.pdf>. Acesso em: 03 abr. 2014.

MONTGOMERY, D.C.; PECK, E.A. Introduction to linear regression analysis. New York: John Wiley e Sons, 1982. 504p.

MORADI, M. et al. Path analysis for yield and related traits in oats. Journal of Science and Technology of Agriculture and Natural Resources, Water and Soil Science, v.9, p.173-180, 2005.

NIRMALAKUMARI, A. et al. Trait association and path analysis for grain yield in oat in thewestern zone of Tamil Nadu. International Journal of Agricultural Science and Research, v.3, p.309-316, 2013.

ROSSETTO, C.A.V:; NAKAGAWA, J. Época de colheita e desenvolvimento vegetativo de aveia preta. Scientia Agricola, v.58, p.731736, 2001. Disponível em: $<$ http://www.scielo.br/pdf/sa/v58n4/6291.pdf $>$. Acesso em: 03 abr. 2014. doi: 10.1590/S0103-90162001000400013.

SALGADO, P. et al. Oats (Avena strigosa) as winter forage for dairy cows in Vietnam: an on-farm study. Tropical Animal Health and Production, v.45, p.561-568, 2013.

TOEBE, M.; CARGNELUTTI FILHO, A. Multicollinearity in path analysis of maize (Zea mays L.). Journal of Cereal Science, v.57, p.453-462, 2013. Disponível em: <http://www.sciencedirect. com/science/article/pii/S0733521013000209>. Acesso em: 03 abr. 2014. doi: 10.1016/j.jcs.2013.01.014.

ZAHERI, A. et al. Correlation and path analysis of grain yield and yield components of oat genotypes under irrigated and rainfed conditions. International Journal of Agronomy and Plant Production, v.4, p.2656-2664, 2013. Disponível em: $<$ http://www.ijappjournal.com/wpcontent/uploads/2013/07/2656-2664.pdf>. Acesso em: 03 abr. 2014. 